\title{
Corrigendum
}

\section{Corrigendum to "The Effect of Botulinum Toxin Type A on Expression Profiling of Long Noncoding RNAs in Human Dermal Fibroblasts"}

\author{
Ying-Ying Miao, ${ }^{1}$ Juan Liu, ${ }^{1}$ Jie Zhu, ${ }^{2}$ Yan-Ling Tao, ${ }^{1}$ Jia-An Zhang, ${ }^{1}$ Dan Luo $\left(\mathbb{D},{ }^{1}\right.$ \\ and Bing-Rong Zhou $\mathbb{D}^{1}$ \\ ${ }^{1}$ Department of Dermatology, The First Affiliated Hospital of Nanjing Medical University, Nanjing 210029, China \\ ${ }^{2}$ Department of Dermatology, The First Affiliated Hospital of Nanjing University of TCM, Nanjing, Jiangsu 210029, China \\ Correspondence should be addressed to Dan Luo; daniluo2005@163.com
}

Received 28 October 2019; Accepted 31 October 2019; Published 26 November 2019

Copyright () 2019 Ying-Ying Miao et al. This is an open access article distributed under the Creative Commons Attribution License, which permits unrestricted use, distribution, and reproduction in any medium, provided the original work is properly cited.

In the article titled "The Effect of Botulinum Toxin Type A on Expression Profiling of Long Noncoding RNAs in $\mathrm{Hu}-$ man Dermal Fibroblasts" [1], there was an error in Figure 4, where the second and third graphs of Figure 4(a) were mistakenly duplicated during the production process. The correct figure is shown below. 


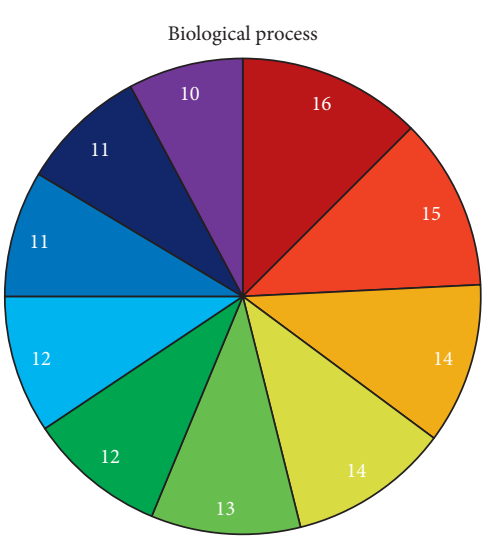

- Small molecule metabolic process

- Regulation of transcription, DNA-templated

$\square$ G-protein coupled receptor signaling pathway

$\checkmark$ Transcription, DNA-templated

Cellular component

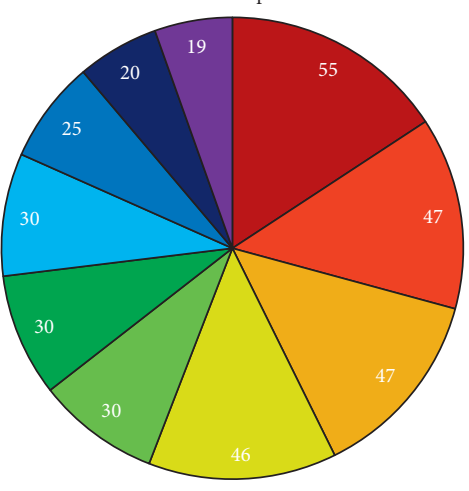

Upregulated GO analysis

Significant terms of differentially expressed gene-BP

Positive regulation of vasodilation

Elastic fiber assembly

Positive regulation of MAPKKK

Negative regulation of smooth.

Type I interferon signaling pathway

Negative regulation of osteoblast...

Complement activatio

Response to virus

Extracellular matrix organizatio

Cell-cell signaling

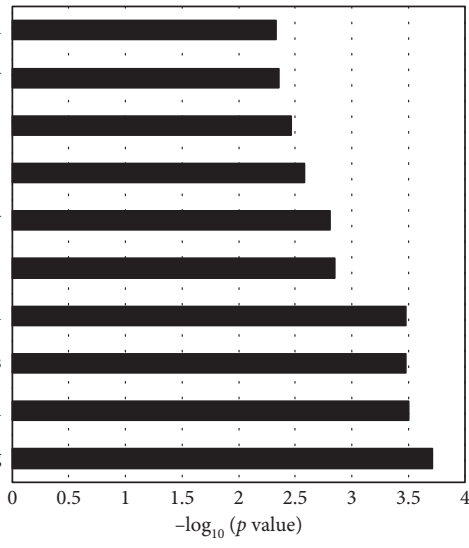

$\square$ Signal transduction

- Positive regulation of transcription from

Extracellular matrix organization

$\square$ Innate immune response

RNA polymerase II promoter

๘ Cell-cell signaling

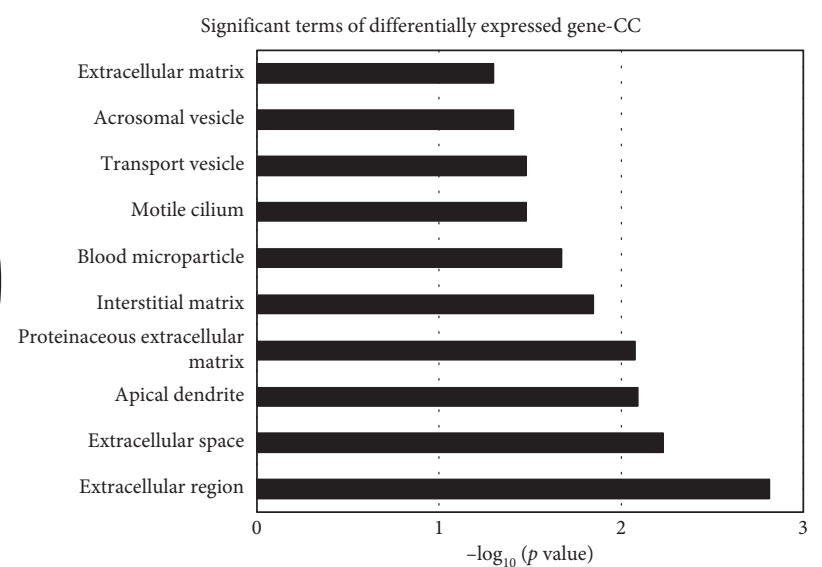

- Cytoplasm

- Integral component of membrane

ธ Extracellular region

- Extracellular exosome

Cytosol

๘ Extracellular space

. Plasma membrane

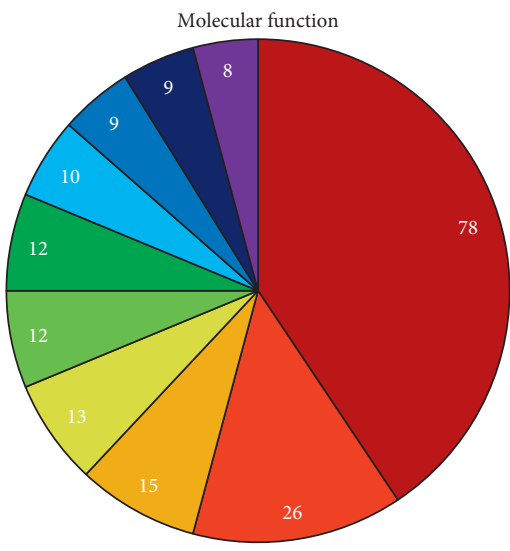

Significant terms of
Neuropeptide receptor activity

Growth factor activity

Insulin receptor substrate binding

Insulin-like growth factor I binding

Integral component of plasma

membrane

- Nucleoplasm

\section{Filamin binding}

Chemokine receptor binding

Phospholipase activator activity

Insulin-like growth factor II binding

Type 1 fibroblast growth factor.

Heparin binding

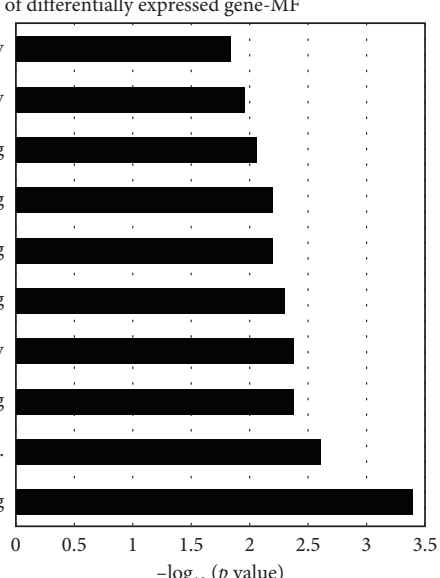

- Zinc ion binding

Protein homodimerization activity

- DNA binding

- Heparin binding

Metal ion bindin

$\square$ ATP binding

- Calcium ion binding

- Transcription factor activity,

sequence-specific DNA binding

(a)

Figure 4: Continued. 


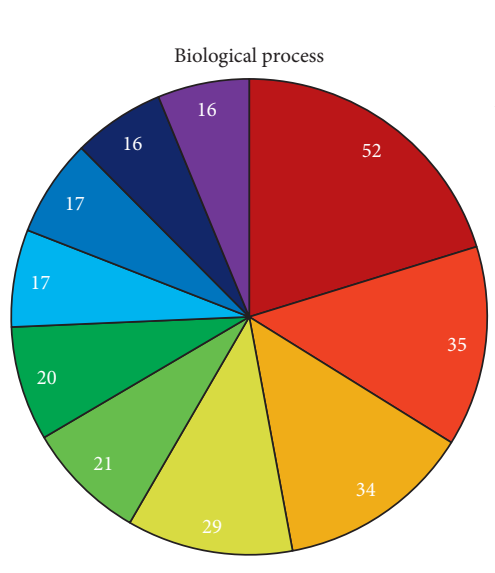

Downregulated GO analysis

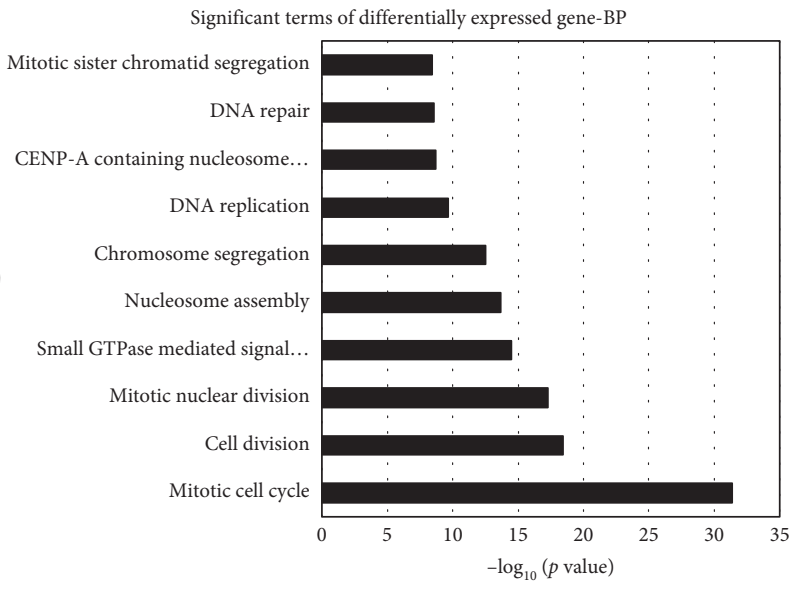

- Mitotic cell cycle

- Small GTPase mediated signal transduction

Cell division

$\square$ DNA repair

- DNA replication

Mitotic nuclear division

口 Nucleosome assembly

- Apoptotic process

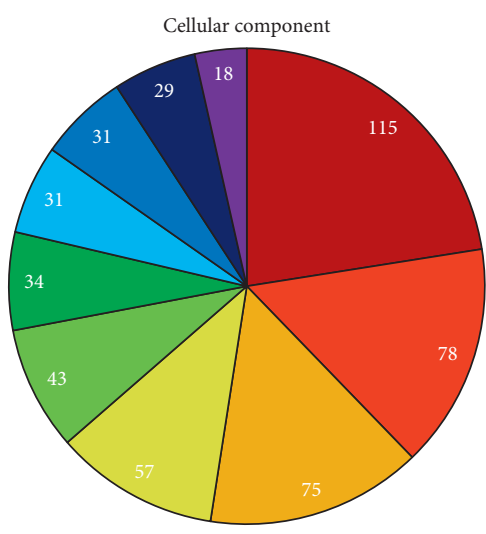

- Transcription, DNA-templated

Significant terms of differentially expressed gene-CC
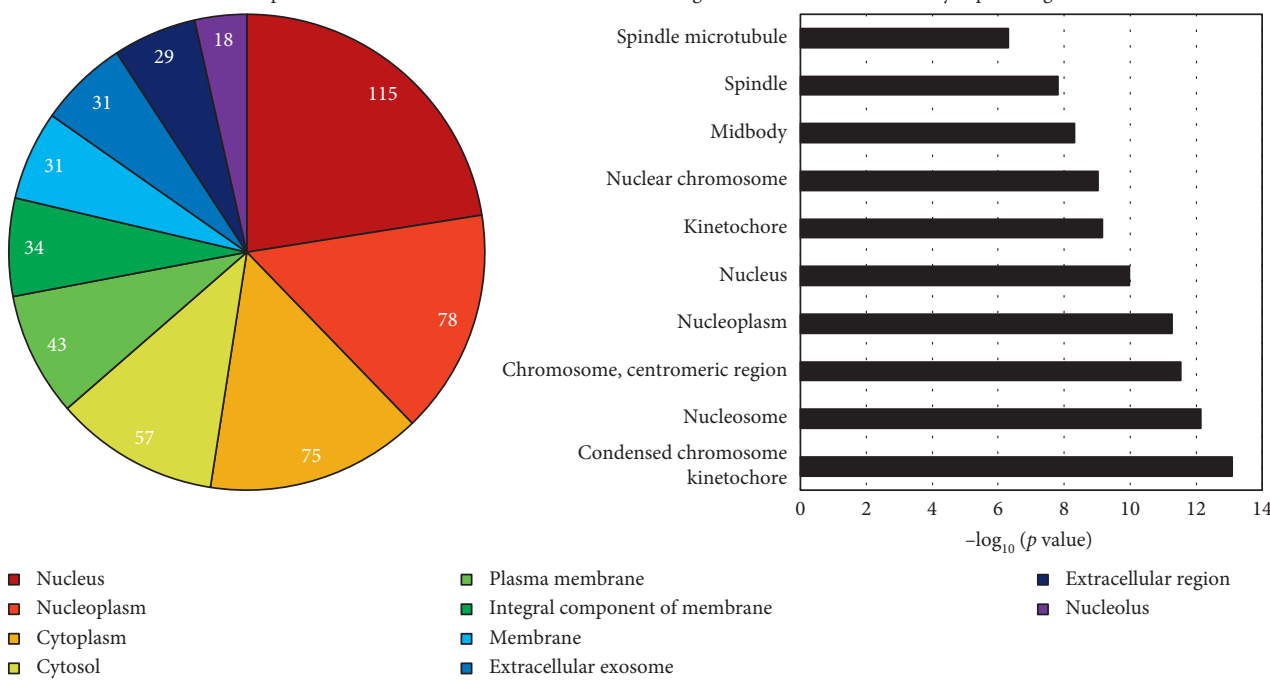

- Nucleoplas

Extracellular exosome
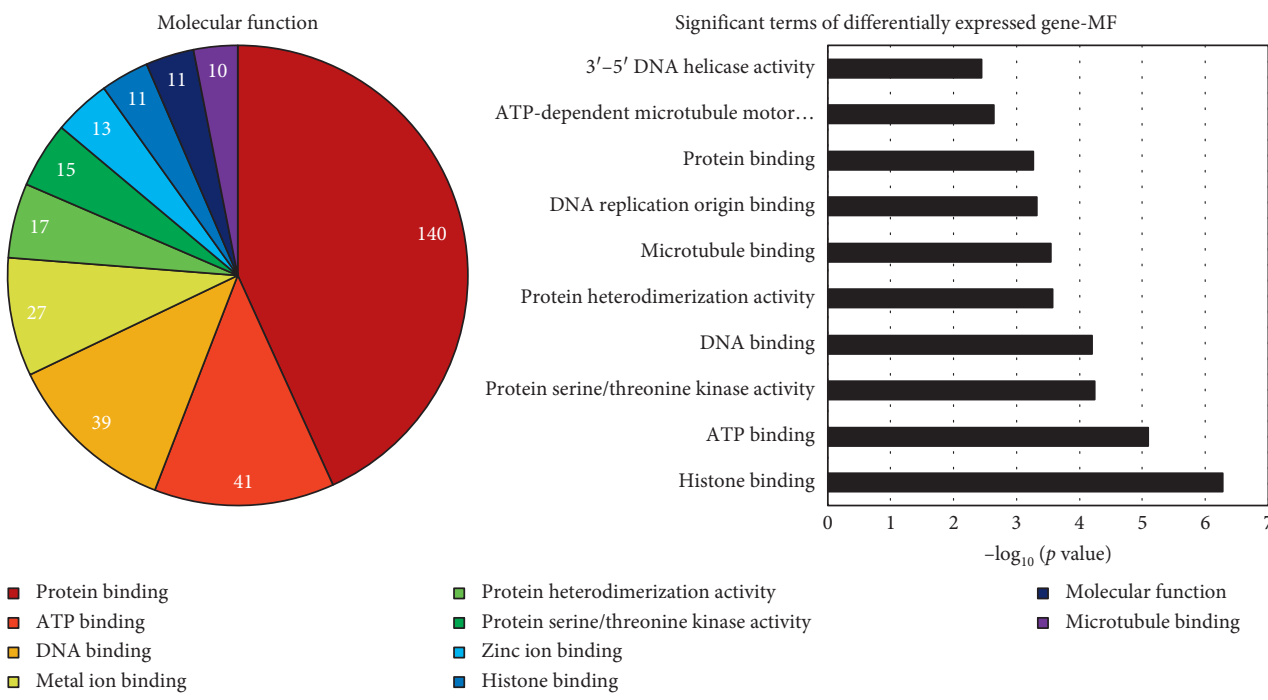

$$
\begin{aligned}
& \text { - Protein binding } \\
& \text { ․ ATP binding } \\
& \square \text { DNA binding } \\
& \square \quad \text { Metal ion binding }
\end{aligned}
$$

Figure 4: Bioinformatic analysis of the differentially expressed genes. The $p$ value denotes the significance of GO terms enrichment in the differentially expressed genes. The lower the $p$ value, the more significant the GO term ( $p$ value $\leq 0.05$ is recommended). We can choose the target genes for further study based on the combination of the analysis provided by GO and the biologic significance. 


\section{References}

[1] Y.-Y Miao, J. Liu, J. Zhu et al., "The effect of botulinum toxin type A on expression profiling of long noncoding RNAs in human dermal fibroblasts," BioMed Research International, vol. 2017, Article ID 2957941, 13 pages, 2017. 


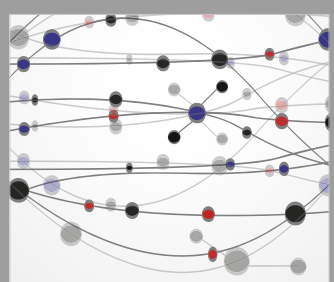

The Scientific World Journal
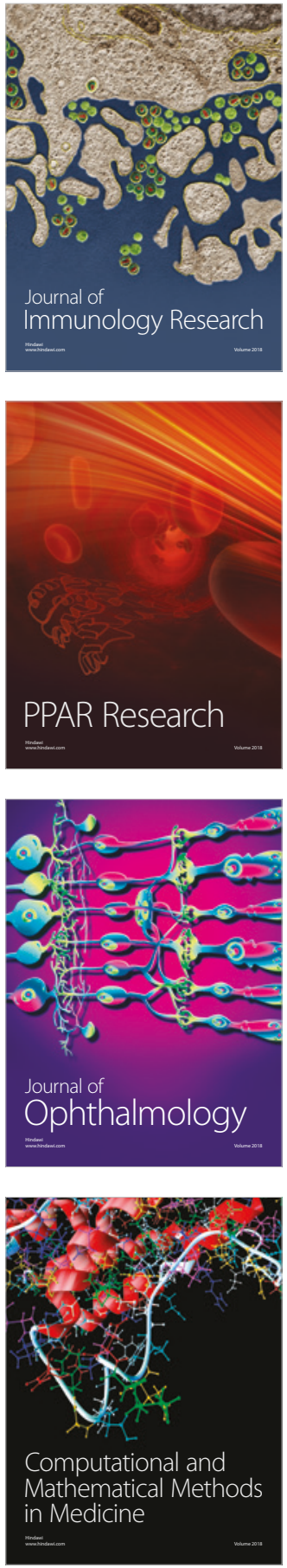

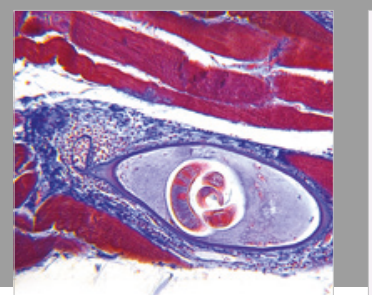

Gastroenterology Research and Practice

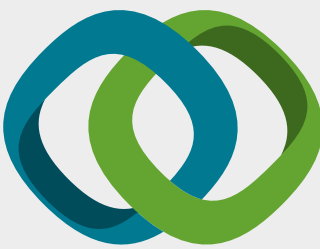

\section{Hindawi}

Submit your manuscripts at

www.hindawi.com
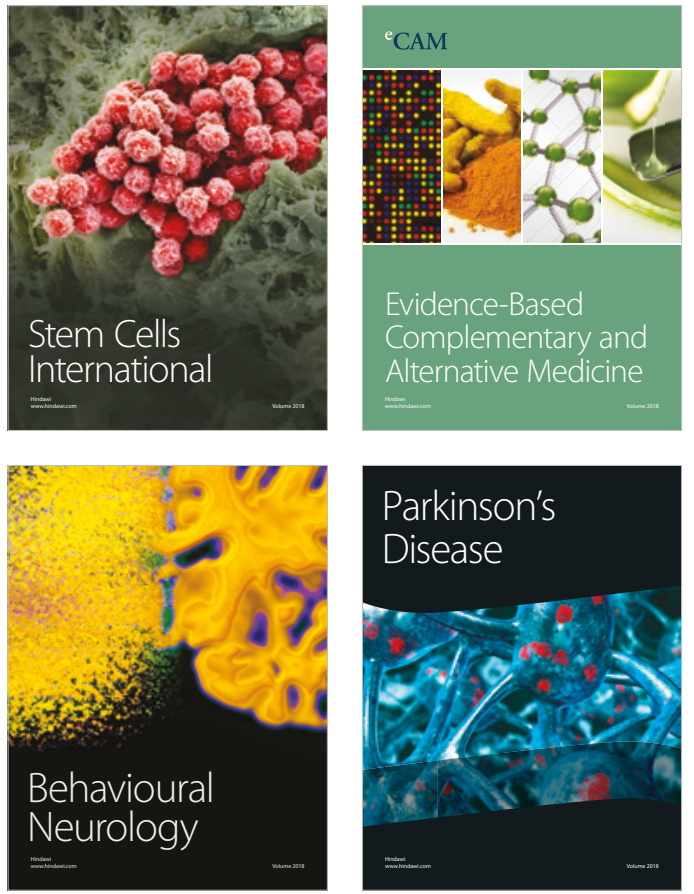

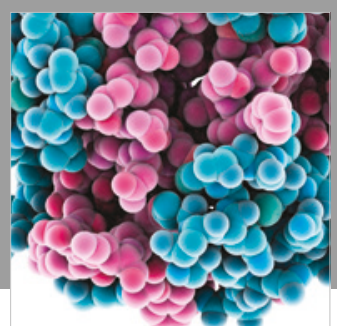

ournal of

Diabetes Research

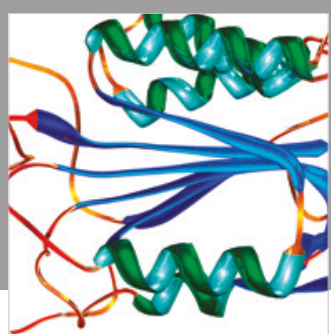

Disease Markers
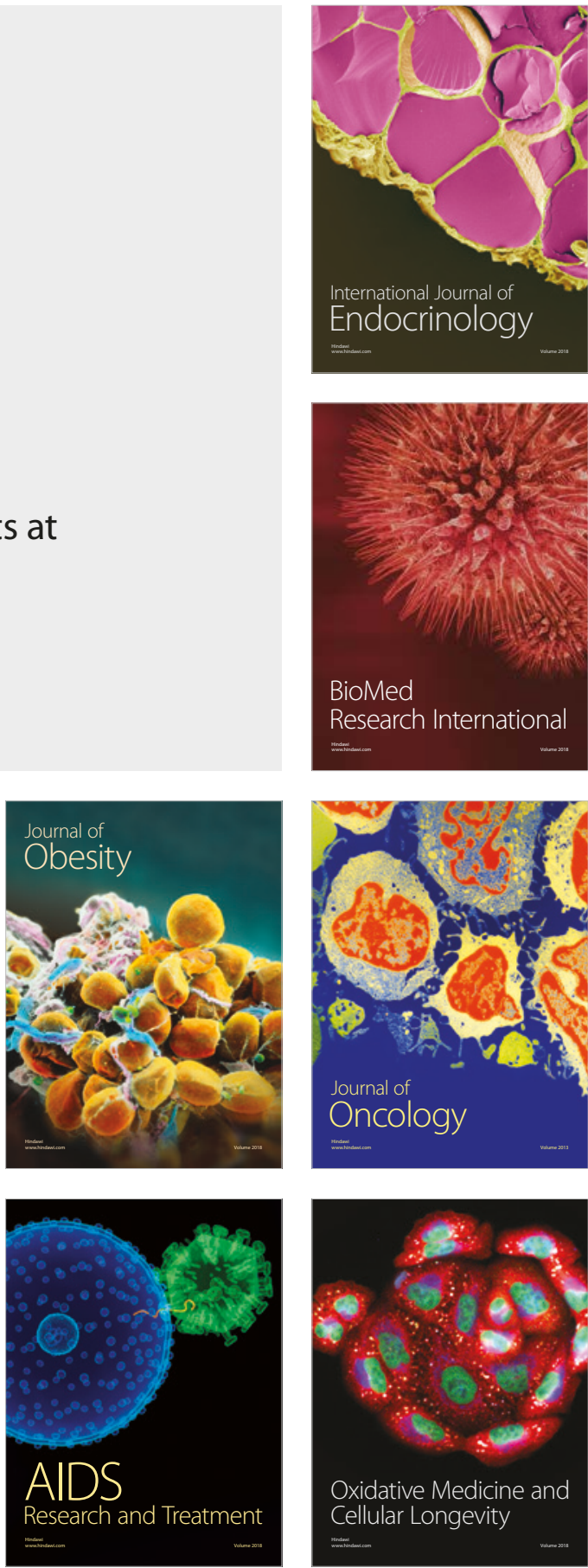